\title{
Waste Valorization and Management
}

\author{
Maria Loizidou ${ }^{1}$
}

Published online: 20 July 2016

(C) Springer Science+Business Media Dordrecht 2016

It is worldwide recognized that huge quantities of waste materials still end up in landfills. In a period of time that environmental awareness becomes more important, emphasis should be drawn on waste prevention and the promotion of reuse, recycling and energy recovery from waste minimizing landfilling. Even more, the current tendency is to move towards new products and chemical building blocks of high value derived from the generated waste offering new options and opportunities at technological level to address modern societies.

Policies and strategies should also contribute towards this direction. At European level, the symbiosis concept and the need to promote circular economy and resource efficiency will influence without any doubt all quantitative targets of the Waste Framework Directive in the near future, being a strong tool to improve the current consumption patterns and the existing waste management status.

This Special Issue entitled: "Waste Management and Valorization" includes the best papers selected from two conferences, namely, the TINOS2015 3rd International Conference on Sustainable Solid Waste Management (http://www.tinos2015.uest.gr) held in Tinos Island, Greece, 2nd-4th July 2015 and the IWWATV 2015 International Conference on Industrial Waste and Wastewater Treatment and Valorization (http://www.

Maria Loizidou

mloiz@chemeng.ntua.gr

1 Unit of Environmental Science and Technology, School of Chemical Engineering, National Technical University of Athens, 9 Heroon Polytechniou Street, Zographou Campus, 15773 Athens, Greece iwwatv.uest.gr) held in Athens, Greece, 21st-23rd May 2015.

Following the ATHENS 2012 and the ATHENS 2014 International Conferences, the TINOS 2015, the third conference of the series, aimed to address the significant issues for sustainable solid waste management through the promotion of effective technologies and success practices, stimulating the interest of scientific community, competent authorities and public on the latest developments in the specific field. Biological Treatment (composting and anaerobic digestion), the treatment at central facilities, waste prevention and separation at source with emphasis on biowaste also constituted priority subjects of the rich conference agenda. Special attention was drawn on sustainable waste management for areas with specific characteristics, such as islands and generally isolated areas, while the success of the conference was evident by the number of participants, the participating countries and the quality of the papers presented.

The Conference provided an opportunity to bring together scientists and professionals from government departments, Municipalities, private institutions, research and education institutions, being a forum for the exchange of the most recent ideas, techniques and experiences in all areas of municipal solid waste management. Last but not the least, the intention of the Conference was to promote further the European Commission policies for effective waste management. The Conference was organized within the LIFE + ISWM-TINOS project (LIFE10 ENV/GR/ 000610) (http://iswm-tinos.uest.gr) dealing with the implementation of an integrated solid waste management scheme for islands.

Furthermore, after the SYMBIOSIS 2014 International Conference that was organized in June 2014, the IWWATV 2015 Conference gave emphasis on industrial 
symbiosis, the sharing of services, utility and by-product resources among industries in order to enhance the added value, reduce costs and improve the environment. Industrial Symbiosis should be considered as one of the solutions to be addressed in order to achieve more efficient processing, resource and energy efficient systems for industry closing the loop. The IWWATV 2015 Conference aimed to inform scientists and industries about the latest developments in the field of industrial waste and wastewater management creating economic and environmental value through symbiotic activities. It was also targeting to contribute towards the improvement of the environmental performance of industries, saving resources, as well as reducing $\mathrm{H}_{2} \mathrm{O}$ and $\mathrm{CO}_{2}$ footprints. The Conference was organized in the framework of the FOODINBIO project (http://foodinbio.uest.gr) and IPP-TEXFOOD project (http://ipp-texfood.uest.gr).

Selected high quality papers presented in the two conferences are included in this Special Issue of Waste and Biomass Valorization. The articles in this issue have been grouped in four categories according to the scientific special orientation. The first category refers to biowaste characterization, composting, anaerobic digestion and biofuel production and includes twelve papers. More specifically, the paper of Vakalis and colleagues deals with the characterization of bio-waste by means of simultaneous thermal analysis and the relation between the heating rate and the decomposition rate. In addition, the parameters that may convert the decomposition from endothermic to exothermic were identified.

The second paper of this category deals with composting and more specifically it presents results from home composting programmes, while the rest of the papers have to do with anaerobic digestion and biofuel production.

The work of Ruffino and colleagues is related to pretreatment of anaerobic digestion of activated sludge, while the other two papers by Dounavis and colleagues and Manara and Zabaniotou refer to glycerol waste. A continuous process was developed aiming at the production of bio-based hydrogen-enriched methane from waste glycerol in a two-stage reactor system in the first paper, while the second one is focused on co-valorization of crude glycerol with conventional and/or renewable resources.

The next two papers are related to biodiesel. Queiroz and colleagues investigated the treatability of wastewater from a biodiesel production industry under (1) aerobic conditions, using domestic activated sludge as inoculum; (2) anaerobic conditions, using sludge from an anaerobic domestic wastewater treatment digester; (3) utilization of wastewater for biogas production. The other one is about microwave-induced pyrolysis for production of sustainable biodiesel from waste sludges by Capodaglio and colleagues, showing that the overall energy balance of the process is not always favorable from the beginning, however, by appropriately "tuning" the wave source and minimizing reflected radiation (lost energy) an energypositive recovery of resources on one side, and considerable reduction of sludge volumes on the other may be achieved.

The eighth paper discusses the exploitation of food industry waste through anaerobic digestion and fermentative hydrogen production in an up-flow column reactor. The next paper has to do with synthesis gas production via the biogas reforming reaction over two different catalysts. The production of different types of bioenergy from oil palm through biorefinery approach constitutes the subject of the next paper. The last two papers of the first category are related to anaerobic digestion. Hlavínek and colleagues worked in the field of biogas production from algal biomass from municipal wastewater treatment, while Stavropoulos and colleagues studied the effect of $\mathrm{pH}$ on continuous biohydrogen production from end-of-life dairy products via dark fermentation.

Management and valorization of agricultural waste is the subject of the second category of the special issue including eight papers. The first paper of this category by Longo and colleagues presented the social aspects related to perceptions of the population for livestock waste management.

The next paper discussed the effects of photon and carbon in Chlorella pyrenoidosa mediated lipid production using Malaysian agricultural wastewater. Next, Daza Serna and colleagues evaluated the production of bioethanol, biogas and electricity as a use of agricultural waste in Colombia through the biorefinery process.

The next two papers were related to winery waste. More specifically, the first one examined the process of aqueous extraction of organics and phenolics from winery wastes (grape marc and wine lees) and the anaerobic digestion of the extracts using a pilot-scale anaerobic digester, while the other one dealt with the first isolation of yeast $\beta$-glucan from a new source, winery spent yeast biomass and its production with an environmental friendly oriented method.

The olive oil by-products were the subject of the following two papers of the second category. In the first of them, a greenhouse-type solar dryer was developed in order to demonstrate an olive oil by-product and agro-residue managing system, which uses solar drying processes for the treatment of olive oil mill residues to decrease the high energy consumption of the drying operations, thus decreasing the environmental impact of these residues. In the other paper the feasibility of microwave-assisted extraction and microwave-assisted enzymatic extraction for the polyphenols recovery from olive kernel and leaves was examined. 
The last paper of this category, the twentieth paper of this Special Issue, examined the effect of several organic solvents, such as hexane, ethanol, acetone, ethyl acetate, ethyl lactate and their mixtures, and extraction temperature on the recovery and isomerization of carotenoids from byproducts of tomato processing. The stability of carotenoids was another area under investigation.

The third category of the special issue refers to phosphorus related research including three papers. Phosphorus is a significant non-renewable element for nutrition and, at the same time, is considered as the primary nutrient responsible for eutrophication. Therefore, the phosphorus related studies are considered of high priority.

The first paper by Raptopoulou and colleagues examines the content and the bioavailability of phosphorus in the phosphate precipitates/solids produced by the treatment of secondary effluent of a wastewater treatment plant.

The second paper of the category deals with cattle slurry and digestates from anaerobic digestion of municipal solid wastes, which are organic wastes containing phosphorus which can potentially be used as a secondary source of this nutrient. This paper of Oliveira and colleagues investigated the effect of $\mathrm{pH}$ in phosphorus release from these wastes using acid and base extraction followed by phosphorus recovery via precipitation, targeting the production of a fertilizer.

The last phosphorus related article, the twenty third of the Special Issue, presents research results in obtaining phosphorous suspension fertilizers on the basis of microbiologically activated sewage sludge ashes and phosphate rock.

Eleven papers have been included in the last category dealing with management and valorization of inorganic waste. The first two deal with glass, the one by Stefanidou and colleagues produced a series of mortars based on white cement and lime as binders, three different aggregate types (river sand, glass spheres available at the market and recycled glass particles from broken bottles), which were tested in order to produce a material with improved properties. The second glass related paper addressed the valorization potential of various industrial wastes, namely fly ash, red mud and ferronickel slag for the production of $\mathrm{CaO}-\mathrm{Al}_{2} \mathrm{O}_{3}-\mathrm{Fe}_{2} \mathrm{O}_{3}-\mathrm{SiO}_{2}$ glass-ceramics.

The following two papers under this category are as follows. The first analyses and evaluates potential applications for several inorganic wastes and intermediate materials, called co-products, generated in the $\mathrm{TiO}_{2}$ pigment production industry through the sulphate method, while the second one focuses on End-of-Life gypsum, a non-inert material appropriate for closed-loop recycling. In particular, a set of performance indicators were developed with the aim to increase the amount of gypsum waste capable of being recycled.

Furthermore, engineering properties of lightweight geopolymer-based material produced from the ternary blend of red mud waste, rice husk ash and diatomaceous earth were optimized with statistical multi-response surface method in the next work by Promentilla and colleagues.

The sixth paper of the last category aimed to investigate the potential valorization of ferronickel slag as a substitute for aggregates in the production of $\mathrm{H}$-shaped concrete paving blocks.

The next two articles of this WAVE Special Issue refer to bottom ash use and valorization. The aim of the work of Rosales and colleagues was to study the influence of the use of recycled mixed aggregates and biomass bottom ash, as replacements for the natural aggregates, on the mechanical behaviour, durability properties and environmental risk of recycled lightweight concrete. The work of Lombardi and Carnevale considered the possibility of improving the quality of bottom ash, by accelerated carbonation, in order to make it suitable for disposal in landfills for inert waste or for the reuse in construction works.

The next work is about inorganic waste related to the environmental performance of an integrated iron and steel plant in Turkey that was evaluated by comparing its resource utilization and emission levels with the BAT associated values.

The thirty third paper deals with the pulp and paper industries, where large volumes of primary and secondary sludge are generated from wastewater treatment. Thermogravimetric analysis was used with the aim to assess the coprocessing of each type of sludge with coal.

In the last paper of the Special Issue an improvement of the methodology used for the implementation of the first industrial symbiosis platform in Italy is proposed, aiming to solve some critical issues encountered during the application phase at a regional scale.

The thirty four papers included in the Special Issue "Waste Management and Valorization" present indicative scientific initiatives and attempts at worldwide level in order to utilise different waste materials, make new products from waste and enhance the protection of environment. The integrated life-cycle thinking should be incorporated in all aspects of waste management so as to identify new potential value chains using waste as resources, moving towards the targets of waste prevention and finding new prospects for the materials that are currently considered as waste components. Innovative processes, modern concepts, new technologies and suitable research financial tools can lead towards modern society towards the 
desired direction, revealing new opportunities for and better future for the next generations.

Concluding, I would like to express my sincere thanks to Prof. Ange Nzihou, the Editor-in-Chief of Waste and
Biomass Valorization for giving the opportunity to publish selected reviewed papers of high quality in a Special Issue of Waste and Biomass Valorization. 